CLINICAL STUDIES / ETUDES CLINIQUES

\title{
THE LONDON HANDICAP SCALE: VALIDATION OF A YORUBA (NIGERIAN) VERSION AMONG
} STROKE SURVIVORS

\section{L'ÉCHELLE DE HANDICAP DE LONDRES: VALIDATION D'UNE VERSION NIGÉRIANE, YORUBA PARMI DES SURVIVANTS D'ACCIDENT VASCULAIRE CÉRÉBRAUX}

HAMZAT Tal-hatu Kolapo 1

PETERS Grace Oluwatitofunmi ${ }^{2}$

1. Department of Physiotherapy, College of Medicine, University of Ibadan, Nigeria

2. Department of Physiotherapy, College of Medical Sciences, University of Maiduguri, Nigeria

E-Mail Contact - HAMZAT Tal-hatu Kolapo : tkhamzat (at) comui (dot) edu.ng

\section{RESUME}

\section{Objectif}

Établir la validité de la version Yoruba de l'échelle d'handicap de Londres (LHS). Le LHS est une mesure valide et fiable de participation qui a été validée dans différentes cultures.

\section{Méthodes}

Une étude de validation a été menée sur 20 patients au décours d'un accident vasculaire cérébral (AVC) durant leur programme de rééducation en ambulatoire. Les participants ont été recrutés par la technique d'échantillonnage, entre février et mai 2008. La version anglaise du LHS a été traduite en Yoruba, langue utilisée dans le sud-ouest du Nigéria et d'autres régions de l'Afrique de l'ouest. Les versions anglaise et Yoruba du LHS ont été complétées par les participants sur un intervalle de deux semaines entre les gestionnaires des deux échelles. La version du LHS Yoruba a été évaluée en utilisant la Spearman's rank order correlation avec la version anglaise.

\section{Résultats}

La corrélation des deux échelles a été sensiblement établie (rho $=0,55 ; p=0.002$ ) exceptée dans 2 domaines.

\section{Conclusion}

Le LHS en langue Yoruba est une traduction valide du LHS anglais et peut être utilisé pour l'étude des survivants post-AVC qui comprennent la langue Yoruba. 


\section{SUMMARY}

\section{Objective}

To evaluate the validity of a Yoruba translated version of the London Handicap Scale (LHS). The LHS is a valid and reliable measure of participation that has been validated in different cultures, but not among Yoruba speaking people of West Africa.

\section{Methods}

A validation study which involved 20 post-stroke patients receiving Physiotherapy on out-patients basis as part of their rehabilitation program. Participants were recruited through purposive sampling technique between February and May, 2008. The English version of the LHS was translated into Yoruba, the language spoken by the Yoruba people of the southwestern Nigeria and other parts of West Africa using a forwardbackward translation process. The English and Yoruba versions of the LHS were completed by the participants with a two-week interval between the administrations of the two scales. Construct validity of the Yoruba LHS was assessed by testing its correlation (using Spearman's rank order correlation) with the English version.

\section{Results}

Total scores on the Yoruba translated version of the LHS correlated significantly with that of the English version (rho $=0.55 ; \mathrm{p}=0.002$ ). Correlation of the domain scores on both scales were significantly correlated with the exception of 2 domains.

\section{Conclusion}

The Yoruba LHS is a valid translation of the English LHS and may be used for the assessment of participation of stroke survivors who comprehend Yoruba language.

\section{INTRODUCTION}

The London Handicap Scale (LHS) is a generic measure of handicap that has been validated in different populations of people with varying health status (9). The LHS measures Handicap on six dimensions viz. mobility, occupation, physical independence, social integration, orientation and economic self-sufficiency (5) and each of the six dimensions is classified on a six point scale (none or Zero to extreme-6). These dimensions of the LHS remain relevant and are represented in the newer construct of participation (6).

Handicap is a construct defined by International Classification of Impairment, Disability and Handicap (ICIDH) as the disadvantage experienced by an individual because of ill health, due to the inability to perform a role that is normal for someone of the same age, gender and background (15). However this construct has been re-conceptualized and superseded by the concept of participation in a more recent framework of the WHO known as the International Classification of Functioning, Disability and Health (ICF) (14). In the ICF model, participation is regarded as a component of health susceptible to influences of environment (14). It refers to the involvement of an individual in life situations in relation to health conditions, bodily functions and structures (14).

Participation is often restricted in people who have survived disease conditions that affect motor function such as stroke (3). Therefore, an important purpose of neuro-rehabilitation is the limitation or prevention of the development of handicap situations (4). Furthermore, because stroke rehabilitation is a restorative process which seeks to hasten and maximize recovery and prepare the stroke survivor to re-integrate as fully as possible into community life, measurement of participation should be central to the evaluation of rehabilitation outcomes (12).

The LHS can be considered a relevant measure of participation which can be utilized for research purposes and evaluation of clinical services (6). However because participation is the result of interaction between an individual's health and contextual factors that include both personal and environmental factors (7), there is need for the availability of a validated and reliable measure of participation in every society such that no population of stroke survivors will be excluded from having its participation status assessed. Furthermore, since participation limitation is a global construct where preferences for or against certain handicap scenarios are considered similar, it is important to have measures of handicap or participation restriction that would be applicable to people in different socio-cultural settings. 
Stroke is an important disease condition seen in clinics and hospitals in the Yoruba communities of Southwestern Nigeria. This neurological condition accounts for majority $(50.4 \%)$ of neurological admissions at the University College Hospital, Ibadan (13). Ogungbo et al (10), from the entries in the stroke registry in Ibadan, reported an increased incidence from 26 per 100,000 studied by Osuntokun et al (11) to 116 per 100,000. In a community based study in Lagos by Danesi et al (1), a crude prevalence of 114 per 100,000 was reported. This cited epidemiological information was obtained from studies carried out in different settings in Southwestern Nigeria. Also the Yoruba tribe, whose native tongue is also called Yoruba language, constitutes $20 \%$ of the entire population of Nigeria, which comprise of 140 million people and 389 ethnic groups (2). Yoruba language is spoken by over 28 million speakers including people in South Western Nigeria and some parts of the South-South and North-Central geopolitical zones of Nigeria as well as some neighbouring West African countries like Republics of Benin and Togo. This study was carried out to translate the LHS which is a valid, reliable and acceptable measure of participation to Yoruba language.

\section{METHODS}

Twenty Stroke freely consenting survivors attending the physiotherapy clinics of four (3 tertiary and 1 secondary) purposively sampled hospitals in South-west Nigeria were recruited using purposive sampling technique. The eligibility criteria for the study include their ability to comprehend, read and write in Yoruba and English languages. In two of the hospitals (A and B), the translated Yoruba version of the LHS was first administered, and then the English version was administered two weeks later a time slecetd based on the presupposition that thier participation would not have changed significantly within 2 weeks. This sequence of administration was reversed in the other two hospitals (C and D) in which participants initially completed the English LHS and later the Yoruba (translated) version. Information such as age, gender, date of stroke onset, and side of body affected was obtained from the patients. Ethical approval was obtained from the Institutional Review Committee (IRC) of the University of Ibadan/University College Hospital, Ibadan.

\section{MATERIALS}

The original (English) version of the London Handicap Scale (LHS) comprises six dimensions of handicap which are: mobility, occupation, physical independence, social integration, and economic self sufficiency. Respondents completed the LHS by selecting one category per dimension indicating their perceived level of disadvantage on a six point scale from none to extreme $(5,6)$. The un-weighted scoring system was used in this study to calculate the total handicap score with obtainable values ranging from 0 (maximum disadvantage) to 30 (no disadvantage). This simple summation procedure has a construct validity of 0.81 reported to be similar to that of the traditional weighted scoring (6).

The LHS was translated into Yoruba using a forward-backward translation process. The English version (original) was translated to Yoruba by a linguist in the University of Ibadan. This was back translated to English language by three independent individuals (a medical doctor and two physiotherapists) who have not perused the English version of the LHS questionnaire prior to the delivery of the Yoruba translation to them. The back translation revealed that the initial translation of "orientation" and "economic self sufficiency" was not adequate. The necessary corrections were made before the Yoruba version of the LHS was administered.

\section{DATA ANALYSIS}

The scores of the six domains of the LHS were calculated using simple summation of un-weighted scores as outlined in the guidelines of the re-evaluated English version. The Wilcoxon signed rank test was utilized for comparison of scores obtained on the Yoruba translated version and the English versions of the LHS. Correlations between the handicap scores (domain and total) of the Yoruba and the English versions of the LHS were analyzed using Spearman Rank Order Correlation Coefficients. Significance level was set at 0.05.

\section{RESULTS}

Twenty stroke survivors participated in the study, 16 males and 4 females, with mean age (SD) of 55.7 (13.4) years. Clinical and demographic characteristics of study participants are presented in table 1 . There were no 
statistical significant differences between the scores of the Yoruba translated versions and the English version for all the six domains of the LHS (Table 2). Correlations between the translated Yoruba version and English version were statistically significant for the total $(r=0.55)$ and domains scores except for domains 3 and 4 (Table 3).

\section{DISCUSSION}

The original (English version) of the London Handicap Scale (LHS) has been reported to be a valid and reliable measure which is acceptable to respondents as it is both brief and easily understood (5). This study provides further evidence for acceptability of the measure as participants were able to complete the questionnaire with no report of difficulty understanding the various items of the measure. This is in conformity with the findings of Lo et al. (8) that handicap is a global construct. There were more males than females in this study because, among the stroke survivors attending the centers, more males were literate in English and Yoruba. The sample was also biased towards participants with higher educational status as ability to read and write in English language was an inclusion criterion for taking part in the study. The construct validity of the 4 domains of the Yoruba version of the LHS was confirmed by their statistically significant correlations with those of the English LHS. However, domain 2 'Looking after yourself' and domain 3 'Work and leisure' were not significantly correlated with the translated (Yoruba) version. Domain 2 seeks the degree of independence with which the respondent looks after him/herself. The responses were time-based, that is the respondents were required to assess the frequency and duration for which assistance, when required, must be available. The time estimation associated with this domain might have introduced an inconsistent interpretation of physical independence to the respondents. This is because different examples of 'looking after yourself' were cited and the frequency of needed assistance was queried. The lack of correlation between the English and Yoruba translated version for the domain which assesses patient's work and leisure activities (domain 3) might be because some of the items under this domain assess constructs that are not characteristic of the Nigerian-Yoruba culture. Such items include gardening, sports hobbies, going on holidays and the information these items convey to the each respondents may vary. This may be because the Yoruba translations of the items are not the frequently used words that feature in the day to day activities of the average Nigerian.

In spite of the two non correlative items afore mentioned, the total scores of the English and Yoruba translated versions were found to correlate significantly. This implies that the Yoruba translated version is a valid translation the original version of the London Handicap Scale

\section{CONCLUSIONS}

This study has demonstrated the construct validity and acceptability of the Yoruba LHS. We therefore suggest that the Yoruba LHS is suitable for use in the evaluation of participation (or participation limitation) of stroke survivors with adequate linguistic (Yoruba) and cognitive skills. 
Table 1: Clinical and Demographic Characteristics of Participants $(\mathrm{N}=20)$

SD: Standard Deviation

\begin{tabular}{|l|c|c|}
\hline \multicolumn{1}{|c|}{ Characteristics } & Mean & S.D. \\
\hline Age & 55.7 & 13.4 (years) \\
\hline Time after stroke onset & 20.05 & 25.76 (months) \\
\hline & $\mathrm{n}$ & $\%$ \\
\hline Gender & & \\
\hline Male & 16 & 80 \\
\hline Female & 4 & 20 \\
\hline Affected side of the body & & \\
\hline Left & 8 & 40 \\
\hline Right & 12 & 60 \\
\hline
\end{tabular}

$\mathrm{n}$ : number of cases

$\%$ : Percentage

Table 2: Wilcoxon's Signed Ranks Test for Comparison of the domain scores of the English and Yoruba versions of the LHS

\begin{tabular}{|l|c|c|c|c|c|c|}
\hline \multicolumn{1}{|c|}{ Domain } & English LHS & & Yoruba LHS & & $\mathbf{Z}$ & $\boldsymbol{p}$ - value \\
\hline & $\mathbf{X}$ & SD & $\mathbf{X}$ & SD & & \\
\hline Mobility & 2.95 & 0.88 & 3.30 & 0.92 & -1.80 & 0.07 \\
\hline Physical Independence & 3.00 & 1.21 & 3.00 & 0.91 & -0.12 & 0.90 \\
\hline Work and Leisure & 2.70 & 1.45 & 2.80 & 1.10 & -0.27 & 0.78 \\
\hline Social Integration & 3.45 & 1.14 & 3.80 & 1.10 & -1.53 & 0.12 \\
\hline Orientation & 4.05 & 1.46 & 4.10 & 1.51 & -0.43 & 0.66 \\
\hline Economic Self-Sufficiency & 2.45 & 1.31 & 2.85 & 1.42 & -1.99 & 0.04 \\
\hline
\end{tabular}

Z: Wilcoxon Signed Ranks Test

Table 3: Correlation between Domain Scores of the English and Yoruba LHS

\begin{tabular}{|c|c|c|c|c|c|c|}
\hline $\begin{array}{c}\text { Yoruba Version } \\
\rightarrow / \\
\text { English Version } \\
\downarrow\end{array}$ & Mobility & $\begin{array}{c}\text { Physical } \\
\text { Independence }\end{array}$ & $\begin{array}{l}\text { Work and } \\
\text { Leisure }\end{array}$ & $\begin{array}{c}\text { Social } \\
\text { Integration }\end{array}$ & Orientation & $\begin{array}{l}\text { Economic Self- } \\
\text { Sufficiency }\end{array}$ \\
\hline Mobility & $0.52^{*}$ & 0.27 & 0.15 & 0.24 & 0.34 & 0.17 \\
\hline $\begin{array}{l}\text { Physical } \\
\text { Independence }\end{array}$ & 0.37 & 0.36 & 0.12 & 0.17 & 0.11 & 0.13 \\
\hline $\begin{array}{l}\text { Work and } \\
\text { Leisure }\end{array}$ & 0.42 & 0.42 & 0.19 & 0.28 & -0.08 & 0.11 \\
\hline Social Integration & $0.63^{*}$ & 0.42 & $0.45^{*}$ & $0.58^{*}$ & 0.37 & 0.42 \\
\hline Orientation & 0.31 & 0.10 & 0.13 & 0.42 & $0.50^{*}$ & 0.39 \\
\hline $\begin{array}{l}\text { Economic Self- } \\
\text { Sufficiency }\end{array}$ & 0.20 & 0.05 & 0.08 & 0.10 & 0.12 & $0.79 *$ \\
\hline
\end{tabular}

* - Statistical significance $(p \leq 0.05)$ 


\section{REFERENCES}

1. DANESI M, OKUBADEJO N, OJINI F. Prevalence of stroke in an urban, mixed-income community in Lagos, Nigeria. Neuroepidemiology 2007; 28: 216- 223

1. DEMOGRAPHICS OF NIGERIA. http://en.wikipedia.org/wiki/Demographics?_of_Nigeria. Accessed on $20 / 2 / 09$

2. DESROSIERS J, DEMERS L, ROBICHAUD L, VINCENT C, BELLEVILLE S, SKA B. Short- term changes in and predictors of participation of older adults after stroke following acute care or rehabilitation. Neurorehabil Neural Repair 2008; 22: 288-297

3. DESROSIERS J, MALOUIN F, BOURBONNAIS D, RICHARDS CL, ROCHETTE A, BRAVO G. Arm and leg impairments and disabilities after stroke rehabilitation: relation to handicap. Clin Rehabil 2003; 17: 666-673

4. HARWOOD RH, GOMPERTZ P, EBRAHIM S. Handicap one year after a stroke: validity of a new scale. J Neurol Neurosurg Psychiatry 1994; 157: 825-829

5. JENKINSON C, MANT J, CARTER J, WADE D, WINNER S. The London handicap scale: a reevaluation of its validity using standard scoring and simple summation. J Neurol Neurosurg Psychiatry 2000; 68: 365-367

6. LEVASSEUR M, DESROSIERS J, ST-CYR TRIBBLE D. Do quality of life, participation and environment of older adults differ according to level of activity? Health and Quality of Life Outcomes 2008; http://www.hqlo.com/content/6/1/30 (Accessed on 31/7/08)

7. LO RS, CHENG JO, WONG EM, TANG WK, WOO J, KWOK J. Handicap and its determinants of change in stroke survivors: one year follow-up study. Stroke 2008; 39:148-153

8. LO RSK, KWOK TCY, CHENG JOY, YANG H, YUAN HJ, HARWOOD R, WOO J. Cross- cultural validation of the London handicap scale and comparison of handicap perception between Chinese and UK population. Age and Ageing 2007; 36: 544-548

9. OGUNGBO B, OGUN SA, USHEWOKUNZE D, RODGERS H, WALKER R. How can we improve the management of stroke in Nigeria, Africa? Africa Journal of Neurological Sciences 2005; 24: 9-19

10. OSUNTOKUN BO, BADEMOSI O, AKINKUGBE OO, OYEDIRAN AB, CARLISLE R. Incidence of stroke in n African city: results from the stroke registry, Ibadan, Nigeria, 1973-1975. Stroke 1979; 10: $205-207$

11.SIBLEY R, KERSTEN P, WARD CD, WHITE B, MEHTA R, GEORGE S. Measuring autonomy in disabled people: validation of a new scale in a UK population. Clin Rehabil 2006; 20: 793-803

12.TALABI OA. A 3-year review of neurologic admission in University College Hospital, Ibadan, Nigeria. West African Journal of Medicine 2003; 22: 150-151

13.WORLD HEALTH ORGANIZATION. International classification of functioning, disability and health: ICF. Geneva: WHO 2001.

14.WORLD HEALTH ORGANIZATION. International classification of impairments, disabilities and handicaps. Geneva: WHO 1980 